\title{
The effects of proteins released from silk mat layers on macrophages
}

\author{
Ju-Won Kim', You-Young Jo ${ }^{2}$, Hae Yong Kweon², Dae-Won Kim ${ }^{3}$ and Seong-Gon Kim ${ }^{4 *}$ (D)
}

\begin{abstract}
Background: The objective of this study was to evaluate the changes in gene expression after incubation of cells with proteins released from different silk mat layers.

Methods: A silk cocoon from Bombyx mori was separated into four layers of equal thickness. The layers were numbered from 1 to 4 (from the inner to the outer layer). The proteins were released by sonication of a silk mat layer in normal saline. The concentration of proteins was determined by spectrophotometry. They were incubated with RAW264.7 cells, and changes in the expression of genes were evaluated by CDNA microarray analysis and quantitative reverse transcriptase-polymerase chain reaction (qRT-PCR).
\end{abstract}

Results: Layer 1 and 4 groups had higher protein concentrations compared to those in layer 2 and 3 groups. The genes associated with inflammation and angiogenesis showed significantly higher expression in layer 1 and 4 groups. The results of qRT-PCR were in agreement with those of the cDNA microarray analysis.

Conclusions: The silk mat from the middle portion of the silkworm cocoon yielded a lower protein release and caused an insignificant change in the expression of genes that are associated with inflammation and angiogenesis.

Keywords: Silk, Inflammation, Angiogenesis inducing agents

\section{Background}

A silk mat is produced from a Bombyx mori silkworm cocoon by separating layers [1, 2]. Because the silkworm cocoon is mainly composed of proteins fibroin and sericin, the silk mat has composition similar to that of the silkworm cocoon [3]. The concentration of fibroin is not much different among the layers [4]. Nonetheless, sericin content generally increases from the inner layer to the outer layer [5]. Aside from these two proteins, seroin and protease inhibitors can be found in the silk mat [4]. The concentrations of these proteins are also different among layers. Seroin and several protease inhibitors are enriched in the innermost layer [4]. When silk mat is implanted into the body, the biological response to silk mat may be different to its origin. However, there has been few studies to illuminate these differences.

Biological response to silk mat will be determined by released protein from silk mat surface or proteins

\footnotetext{
* Correspondence: kimsg@gwnu.ac.kr

${ }^{4}$ Department of Oral and Maxillofacial Surgery, College of Dentistry,

Gangneung-Wonju National University, Gangneung 25457, Republic of Korea Full list of author information is available at the end of the article
}

undergone proteolysis by macrophages. Sericin is an adhesive protein and encompasses fibers [6,7]. Sericin is water soluble and is released from a silk mat in a fragmented form [8]. Because the concentrations of sericin are different among the layers, the released protein concentration is also different among the layers [9]. Seroin and some protease inhibitors are hydrophilic [4] and can be released from each layer.

The amount of protein released into normal saline is lower for the middle portion of the silkworm cocoon $[3,9]$. These protein solutions are mainly composed of sericin, which is known to be a degumming product [9]. Nevertheless, that study did analyze the proteins between 15 and $50 \mathrm{kDa}$ [9]. For example, the molecular weight of seroin is under $15 \mathrm{kDa}$ [4]. Therefore, proteins other than sericin may be present in the solution containing released proteins. These protein solutions increase the expression level of tumor necrosis factor- $\alpha$ (TNF- $\alpha$ ) in macrophages [9]. The expression level of TNF- $\alpha$ is generally proportional to the protein concentration in the solution being applied [9]. The detailed TNF- $\alpha$ expression pattern is different between the solutions derived from the innermost layer and from the 
outermost layer [9]. Because the concentrations of seroin and of protease inhibitors are also different among the layers [4], the difference in expression patterns may be due to the compositional dissimilarity.

Aside from TNF- $\alpha$ quantification, there have been few studies about the gene expression changes in macrophages under the influence of the silk mat-derived soluble proteins. Recently, a silk mat was approved by the Korean Food and Drug Administration for clinical trials (SPENSER-TS101 approved at November 27, 2015). As a silk mat is at the final stage of evaluation for clinical application, detailed information on the released proteins' effects are important. cDNA microarrays have been widely used for the screening of overall genetic expression changes in cells or tissues [10]. The purpose of this study was to screen gene expression changes after application of a silk mat-derived protein solution to macrophages. Quantitative reverse transcriptase-polymerase chain reaction (qRT-PCR) analysis was performed on selected genes to confirm the microarray results.

\section{Methods}

Preparation of a solution of proteins released from a silk mat Cocoons of Bombyx mori were kindly gifted by the Rural Development Administration (Wanju, Korea). A cocoon was cut and separated into four layers of the same thickness. Each layer was designated as layer 1 through layer 4 (from the inner to the outer layer). To acquire the proteins released from each silk layer, the silk mats of each layer $(2 \mathrm{~g})$ were placed into $50 \mathrm{~mL}$ of normal saline at $25{ }^{\circ} \mathrm{C}$. To accelerate protein release from each silk mat, normal saline was sonicated with a silk mat for $4 \mathrm{~h}$. After removal of the silk mat, the protein concentration in normal saline was determined by spectrophotometry at $280 \mathrm{~nm}$. The standard curve was constructed via measurement of bovine albumin concentration.

\section{Cell cultures and application of a protein solution}

RAW264.7 cells (KCLB No. 40071) were used for studying gene expression profiles under the influence of the proteins released from a silk mat. The detailed procedure was in accordance with our previous publication [9]. The culture medium was Dulbecco's modified Eagle's medium-high glucose (PAA Laboratories, Linz, Austria) supplemented with $1 \%$ of a penicillin/streptomycin solution $(100 \times)$ and $10 \%$ of fetal bovine serum (FBS). The cells were grown to $80 \%$ confluence at $37{ }^{\circ} \mathrm{C}$ in an atmosphere containing $5 \%$ of $\mathrm{CO}_{2}$ and at $99 \%$ relative humidity. Then, the culture medium was changed to the same composition without FBS. After measurement of the protein concentrations, the same volume of a protein solution from each layer $(750 \mu \mathrm{L})$ was added into the culture medium of RAW264.7 cells. The same amount of normal saline was added to the medium as a control.
During incubation with the protein solution, total RNA from each group was isolated at 2 and $8 \mathrm{~h}$ after initiation of the incubation. For qRT-PCR, total RNA from each group was collected at 2,8 , and $24 \mathrm{~h}$ during the incubation.

\section{CDNA microarray analysis and qRT-PCR}

The quality of total RNA was evaluated on an Agilent 2100 Bioanalyzer (Agilent Technologies, Santa Clara, CA, USA). RNA integrity number of all the samples was greater than 7.0 and met the criterion for the subsequent microarray analysis. Commercially available microarray chips for mouse genes (Agilent MouseGE $4 \times 44 \mathrm{~K}$, Agilent Technologies) were used. By means of Agilent's Low RNA Input Linear Amplification kit plus (Agilent Technologies), extracted total RNA was subjected to amplification and labeling. After unhybridized probes were washed out, chips were scanned, and the scanned images were analyzed in the Feature Extraction Software (Agilent Technologies). Normalization and clustering were performed in GeneSpring software (Agilent Technologies). For comparative purposes, gene expression in the untreated control was also analyzed. The comparison of the expression of genes between each layer group and the no-treatment control was performed in the generated scatter plot.

Three genes among inflammation-associated genes were selected and analyzed by qRT-PCR for confirmation. The primers for the interleukin $1 \beta(I l 1 \beta)$ were F: 5 '-AACCATGGCACATTCTGTTC-3' and R: 5'-AGGTAAGTGGTTGCCCATCA-3'. Those for interleukin 18 (Il18) were F: 5'-GTTCTCTGTGGTTCCATGCT-3' and R: 5'-CTGGAGGTTGCAGAAGATGT-3'. That for Tnfo were F: 5'-ACAAGATGCTGGGACAGTGA-3' and R: 5'-GCTCCAGTGAATTCGGAAAG-3'. That for glyceraldehyde 3-phosphate dehydrogenase (Gapdh) were F: 5'GGCATTGCTCTCAATGACAA-3' and R: 5' 'ATGTAGGCCATCAGGTCCAC-3'. Reverse-transcribed total RNA served as a template in each PCR. The threshold cycle $(\mathrm{Ct})$ values were determined. Relative expression was calculated as a ratio of the selected gene's expression to the expression of Gapdh. Measurements were taken three times, and the average value served for comparison.

\section{Statistical analysis}

Cluster analysis was carried out in Gene Cluster 3.0 (Stanford University, CA, USA). Genes were filtered, and data were normalized. For hierarchical analysis, genes were clustered, and uncentered correlation served as a similarity metric. The clustering method was centroid linkage. For the comparison of gene expression levels by qRT-PCR, ANOVA was performed. As the post hoc analysis, Bonferroni's test was conducted. The significance level was set to $P<0.05$. 


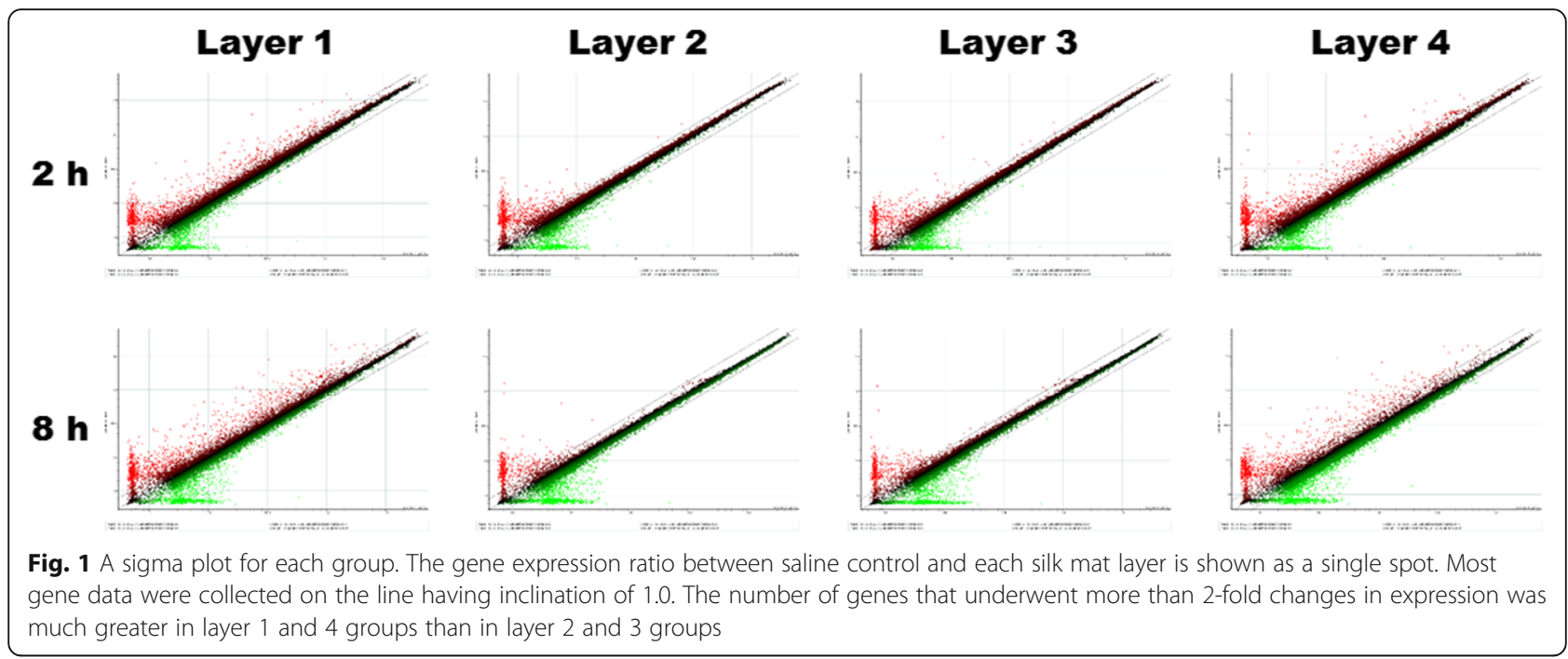

\section{Results}

The protein concentration in each solution was 10.08, 3 . $37,3.47$, and $8.41 \mu \mathrm{g} / \mathrm{mL}$ for layer groups $1,2,3$, and 4 , respectively. After addition of each solution to cell culture, changes of gene expression were studied. The scatter plots for each array are shown in Fig. 1. The number of genes manifesting significant fold changes (/fold ratio/>2) was greater in layer 1 and 4 groups than in layer 2 and 3 groups. Selected genes were subjected to cluster analysis (Fig. 2). The genes in the transforming growth factor- $\beta$ (TGF- $\beta$ ) family and the genes associated with inflammation showed higher levels of expression in layer 1 and 4 groups than in layer 2 and 3 groups. Most genes showed a stable level of expression until 8 h. Nevertheless, the expression of some genes decreased at $8 \mathrm{~h}$.

Table 1 shows the summary of significantly differentially expressed genes. Layer 1, 2, and 4 groups showed significantly lower expression of fibroblast growth factor-2 (Fgf2) at $8 \mathrm{~h}$ after addition of a protein solution $(P<0.05)$. The layer 1 group showed significantly higher mRNA expression of Fgf7 at $8 \mathrm{~h}(P<0.05)$. In contrast, the expression of

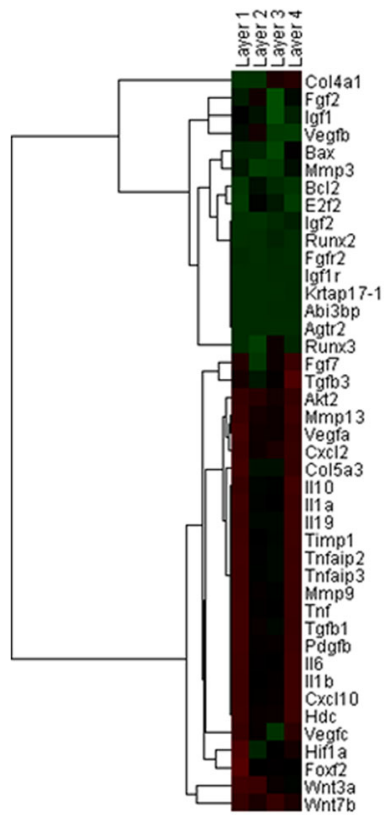

2 hr

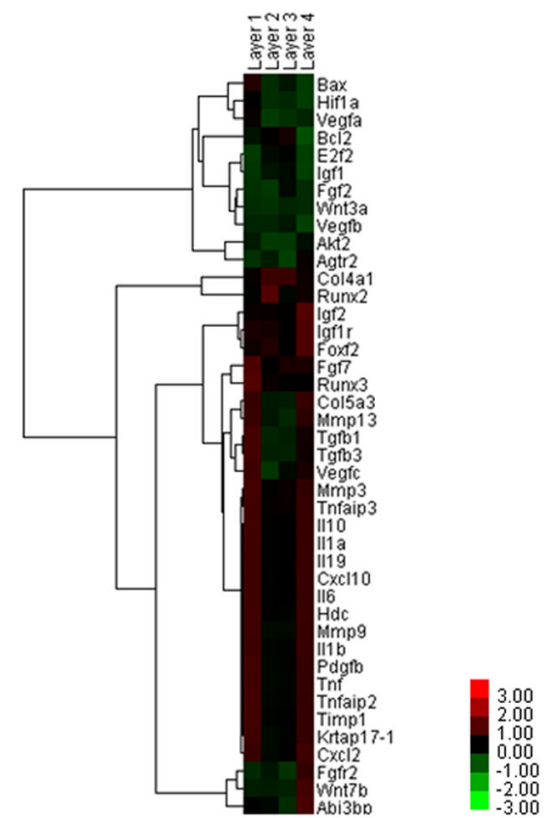

$8 \mathrm{hr}$

Fig. 2 A gene tree with cluster analysis. The genes associated with inflammation and angiogenesis were highly expressed in layer 1 and 4 groups at $2 \mathrm{~h}$. The elevated expression of some genes persisted until $8 \mathrm{~h}$ 
Table 1 Summary of microarray results

\begin{tabular}{|c|c|c|c|c|c|}
\hline Gene & Observation & Layer 1 & Layer 2 & Layer 3 & Layer 4 \\
\hline \multirow[t]{2}{*}{ Fgf2 } & $2 \mathrm{~h}$ & -0.731 & 0.450 & $-1.961^{*}$ & -0.247 \\
\hline & $8 \mathrm{~h}$ & $-2.731^{*}$ & $-3.140^{*}$ & -0.591 & $-2.441^{*}$ \\
\hline \multirow[t]{2}{*}{ Fgf7 } & $2 \mathrm{~h}$ & 0.483 & -0.720 & 0.180 & 0.802 \\
\hline & $8 \mathrm{~h}$ & 1.772 & -0.001 & 0.575 & 0.640 \\
\hline \multirow[t]{2}{*}{ Igfir } & $2 \mathrm{~h}$ & $-3.106^{*}$ & $-3.101^{*}$ & $-2.943^{*}$ & $-2.953^{*}$ \\
\hline & $8 \mathrm{~h}$ & 0.087 & 0.067 & -0.002 & 0.246 \\
\hline \multirow[t]{2}{*}{ Col4ar } & $2 \mathrm{~h}$ & -0.087 & -0.083 & 0.048 & 0.066 \\
\hline & $8 \mathrm{~h}$ & 0.364 & $2.300^{*}$ & $2.145^{*}$ & 0.484 \\
\hline \multirow[t]{2}{*}{ Fgfr2 } & $2 \mathrm{~h}$ & $-3.857^{*}$ & $-4.213^{*}$ & $-3.848^{*}$ & $-4.119^{*}$ \\
\hline & $8 \mathrm{~h}$ & -0.126 & -0.067 & -0.157 & 0.157 \\
\hline \multirow[t]{2}{*}{ Hif1a } & $2 \mathrm{~h}$ & $1.435^{*}$ & -0.641 & 0.023 & 0.419 \\
\hline & $8 \mathrm{~h}$ & -0.023 & -0.599 & -0.518 & -0.817 \\
\hline \multirow[t]{2}{*}{1116} & $2 \mathrm{~h}$ & $3.001^{*}$ & 0.067 & 0.269 & $3.102^{*}$ \\
\hline & $8 \mathrm{~h}$ & $3.233^{*}$ & -0.308 & -0.107 & $2.993^{*}$ \\
\hline \multirow[t]{2}{*}{116} & $2 \mathrm{~h}$ & $5.252^{*}$ & 0.250 & 0.162 & $5.356^{*}$ \\
\hline & $8 \mathrm{~h}$ & $5.676^{*}$ & 0.058 & -0.080 & $5.085^{*}$ \\
\hline \multirow[t]{2}{*}{$1 / 19$} & $2 \mathrm{~h}$ & $1.236^{*}$ & -0.134 & -0.168 & $1.298^{*}$ \\
\hline & $8 \mathrm{~h}$ & $3.463^{*}$ & -0.054 & 0.106 & $3.106^{*}$ \\
\hline \multirow[t]{2}{*}{ Mmp3 } & $2 \mathrm{~h}$ & -0.864 & $-2.123^{*}$ & $-2.006^{*}$ & -0.511 \\
\hline & $8 \mathrm{~h}$ & $2.714^{*}$ & -0.113 & 0.436 & $1.954^{*}$ \\
\hline \multirow[t]{2}{*}{ Mmp9 } & $2 \mathrm{~h}$ & $1.630^{*}$ & 0.173 & -0.063 & $1.514^{*}$ \\
\hline & $8 \mathrm{~h}$ & $1.171^{*}$ & -0.195 & -0.162 & $1.021^{*}$ \\
\hline \multirow[t]{2}{*}{ Pdgfb } & $2 \mathrm{~h}$ & $2.385^{*}$ & 0.166 & 0.241 & $2.155^{*}$ \\
\hline & $8 \mathrm{~h}$ & $2.455^{*}$ & -0.218 & -0.137 & $2.021^{*}$ \\
\hline \multirow[t]{2}{*}{ Tnfa } & $2 \mathrm{~h}$ & $1.462^{*}$ & 0.086 & 0.026 & $1.301^{*}$ \\
\hline & $8 \mathrm{~h}$ & $1.443^{*}$ & -0.170 & -0.110 & $1.182^{*}$ \\
\hline \multirow[t]{2}{*}{ Tnfaip3 } & $2 \mathrm{~h}$ & $2.231^{*}$ & -0.084 & -0.254 & $2.119^{*}$ \\
\hline & $8 \mathrm{~h}$ & $3.420^{*}$ & 0.378 & 0.446 & $2.957^{*}$ \\
\hline \multirow[t]{2}{*}{ Wnt3a } & $2 \mathrm{~h}$ & $4.117^{*}$ & $3.730^{*}$ & 0.666 & -0.270 \\
\hline & $8 \mathrm{~h}$ & $-3.989^{*}$ & $-4.493^{*}$ & $-3.257^{*}$ & $-3.897^{*}$ \\
\hline \multirow[t]{2}{*}{ Wnt7b } & $2 \mathrm{~h}$ & $3.949^{*}$ & $2.108^{*}$ & $4.070^{*}$ & $2.147^{*}$ \\
\hline & $8 \mathrm{~h}$ & -0.630 & -0.570 & -0.704 & $1.458^{*}$ \\
\hline
\end{tabular}

${ }^{*} P<0.05$ when compared to the saline-treated control

Fgf fibroblast growth factor, Col collagen, Igf insulin-like growth factor, Hif hypoxia-inducible factor, II interleukin, $M m p$ matrix metalloproteinase, Pdgf platelet-derived growth factor, Tnf tumor necrosis factor

insulin-like growth factor-1-receptor (Igf1r) was significantly higher in all groups at $2 \mathrm{~h}(P<0.05)$. The gene expression levels of interleukin and Tnf families were higher in layer 1 and 4 groups. Matrix metalloproteinase$3(\mathrm{Mmp} 3)$ and $M m p 9$ also manifested significantly higher gene expression in layer 1 and 4 groups at $8 \mathrm{~h}(P<0.05)$. Platelet-derived growth factor (Pdgf) is associated with angiogenesis and showed significantly higher gene expression in layer 1 and 4 groups at 2 and $8 \mathrm{~h}(P<0.05)$. Hypoxia-inducible factor-1- $\alpha$ (Hif1 $\alpha$ ) was significantly upregulated in the layer 1 group at $2 \mathrm{~h}(P<0.05)$. The Wnt signaling pathway is closely associated with angiogenesis. Wnt3a was overexpressed in layer 1 and 2 groups at $2 \mathrm{~h}$ but was significantly underexpressed at $8 \mathrm{~h}$ in all groups $(P<0.05)$. In the case of $W n t 7 b$, it was significantly overexpressed in all groups at $2 \mathrm{~h}$, but the elevated level of expression persisted only in the layer 4 group $(P<0.05)$.

For confirmation of the microarray results, qRT-PCR was conducted, and the results are demonstrated in Fig. 3. The expression of $I l 1 b, I l 18$, and $T n f \alpha$ was significantly higher in layer 1 and 4 groups at 2, 8, and $24 \mathrm{~h}$ after addition of the protein solution $(P<0.05)$. Compared to layer 1 and 4 groups, those expression levels in layer 2 and 3 groups manifested insignificant changes throughout the observation period.

\section{Discussion}

In this study, a gene expression profile of macrophages was evaluated by cDNA microarray and qRT-PCR analyses. The proteins released from layers 1 and 4 increased the expression levels of genes associated with angiogenesis and inflammation. The main protein in the solution was likely sericin because $20-30 \%$ of a silk mat is composed of sericin, and proteins other than sericin and fibroin constitute less than $1-2 \%$ of a silk mat [5]. Therefore, these differences among groups may be due to the differences in sericin content among the layers.

\section{Genes associated with inflammation}

Kundu et al. [11] reported that a sericin-coated dental implant did not significantly increase TNF- $\alpha$ and IL-1 $\beta$ expression in macrophages. Low level of sericin does not significantly increase TNF- $\alpha$, but high level of sericin increases TNF- $\alpha$ significantly [9]. Accordingly, the expression levels of pro-inflammatory cytokines may be dependent on the concentration of applied sericin [9]. In case of $I l 19$, its expression level in layer 1 and 4 groups was elevated at $8 \mathrm{~h}$ as compared to that at $2 \mathrm{~h}$ (Table 1 ). When the Il19 gene is inactivated in mice, the expression level of pro-inflammatory cytokines increases [12].

The expression of Hif1 $\alpha$ is elevated by proinflammatory cytokines such as IL1A, IL6, and TNF $\alpha$ [13]. The expression of Hifl $\alpha$ was elevated here at $2 \mathrm{~h}$ after addition of the protein solution in the layer 1 group. If a HIF1A inhibitor is applied, then protein expression of IL6 and TNF $\alpha$ decreases [14]. Accordingly, there is a close association between Hifl $\alpha$ expression and pro-inflammatory cytokines' expression [15].

\section{Genes associated with angiogenesis}

For vascular regeneration, the basement membrane of endothelial cells should undergo proteolysis, and MMPs are involved in this process [16]. The degradation of the basement membrane proteins can cause a release of free 


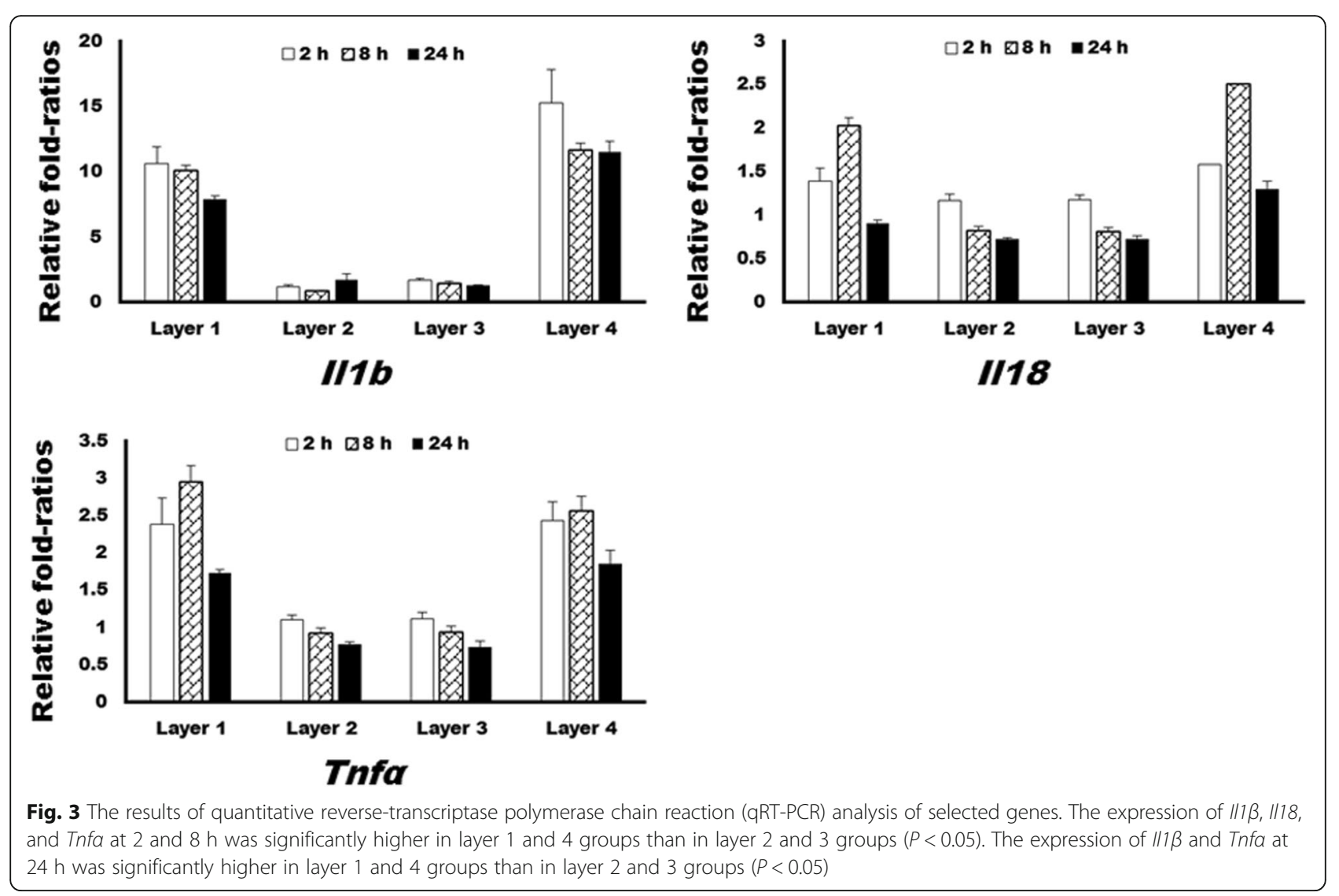

vascular endothelial growth factor (VEGF) [17]. In the present study, $M m p 3$ and $M m p 9$ showed elevated levels of gene expression in layer 1 and 4 groups (Table 1). Wint $3 a$ and Wint $7 b$ were significantly overexpressed at $2 \mathrm{~h}$ after addition of a protein solution in layer 1 and 4 groups $(P<0.05)$. The expression of Wnt3a is closely related to macrophage-mediated angiogenesis under pathological conditions [18]. Without WNT7B, transcription of Vegfa is strongly suppressed [19]. Consequently, the gene expression levels of Mmp3, Mmp9, and $P d g f b$ were high in layer 1 and 4 groups, which showed high levels of Wint3a and Wint7b expression. All of them are closely related to angiogenesis.

Hypoxic stress can increase the expression of $P d g f b$ in hepatic cancer cells, and this change leads to cellular proliferation and elevated Vegf expression [20]. When zoledronate is applied to pre-osteoclasts, the $P d g f b$ expression decreases and results in suppressed angiogenesis [21]. In osteogenesis, angiogenesis is a vital component, and PDGFB is the main regulator [22]. Besides, PDGFB is important for the healing process after vascular injury [23]. Hifl $\alpha$ is induced by hypoxic stress and associated with angiogenesis [13]. In our study, Hif1 $\alpha$ and Pdgfb were overexpressed at $2 \mathrm{~h}$ in the layer 1 group (Table 1 ). This group's increased levels of gene expression seemed to be due to the activation of angiogenesis induced by silk matderived proteins.

\section{Conclusions}

Silk mat-derived protein solution increased the genes associated with inflammation and angiogenesis in macrophages as originated in a layer-dependent manner. For the development of biomaterials from a silk mat, different biological properties of each layer should be considered.

\section{Abbreviations}

Fgf: Fibroblast growth factor; Gapdh: Glyceraldehyde 3-phosphate dehydrogenase; Hif1a: Hypoxia-inducible factor-1-a; Igf1r: Insulin-like growth factor-1receptor; II: Interleukin; Mmp: Matrix metalloproteinase; Pdgf: Platelet-derived growth factor; qRT-PCR: Quantitative reverse transcriptase-polymerase chain reaction; TGF- $\beta$ : Transforming growth factor- $\beta$; TNF-a: Tumor necrosis factor$a_{i}$ VEGF: Vascular endothelial growth factor

\section{Acknowledgements}

This work was carried out with the support of "Cooperative Research Program for Agriculture Science and Technology Development (Project no. PJ01313902)" Rural Development Administration, Republic of Korea.

\section{Availability of data and materials}

Raw data are available and will be provided by the corresponding author on request.

Authors' contributions

KJW and KDW did most the cellular experiment. JYY and KHY did the material preparation and analysis. KSG and KJW designed this experiment. 
KSG and KJW wrote the manuscript and did the critical review on the experimental process. All authors read and approved the final manuscript.

\section{Competing interests}

The authors declare that they have no competing interests.

\section{Publisher's Note}

Springer Nature remains neutral with regard to jurisdictional claims in published maps and institutional affiliations.

\section{Author details}

'Department of Oral and Maxillofacial Surgery, Sacred Heart Hospital, Hallym University, Jukheon gil 7, Gangneung, Gangwondo 25457, Republic of Korea. ${ }^{2}$ Sericultural and Apicultural Materials Division, National Academy of Agricultural Science, Wanju-gun 55365, Republic of Korea. ${ }^{3}$ Department of Oral Biochemistry, College of Dentistry, Gangneung-Wonju National University, Gangneung 25457, Republic of Korea. ${ }^{4}$ Department of Oral and Maxillofacial Surgery, College of Dentistry, Gangneung-Wonju National University, Gangneung 25457, Republic of Korea.

Received: 28 February 2018 Accepted: 9 April 2018

Published online: 25 May 2018

\section{References}

1. Seok H, Kim MK, Kim SG, Kweon H (2014) Comparison of silkworm-cocoonderived silk membranes of two different thicknesses for guided bone regeneration. J Craniofac Surg 25:2066-2069

2. Kim SG, Kim MK, Kweon H, Jo YY, Lee KG, Lee JK (2016) Comparison of unprocessed silk cocoon and silk cocoon middle layer membranes for guided bone regeneration. Maxillofac Plast Reconstr Surg 38:11

3. Kweon H, Jo YY, Seok H et al (2017) In vivo bone regeneration ability of different layers of natural silk cocoon processed using an eco-friendly method. Macromol Res 25:806-816

4. Zhang Y, Zhao P, Dong Z et al (2015) Comparative proteome analysis of multi-layer cocoon of the silkworm, Bombyx mori. PLoS One 10:e0123403

5. Mondal M, Trivedy K, Kumar N (2007) The silk proteins, sericin and fibroin in silkworm, Bombyx mori Linn.-a review. Casp J Envir Sci 5:63-76

6. Ha Y, Park YW, Kweon H, Jo YY, Kim SG (2014) Comparison of the physical properties and in vivo bioactivities of silkworm-cocoon-derived silk membrane, collagen membrane, and polytetrafluoroethylene membrane for guided bone regeneration. Macromol Res 22:1018-1023

7. Chen F, Porter D, Vollrath F (2012) Morphology and structure of silkworm cocoons. Mater Sci Eng C 32:772-778

8. Mandal BB, Priya AS, Kundu SC (2009) Novel silk sericin/gelatin 3-D scaffolds and 2-D films: fabrication and characterization for potential tissue engineering applications. Acta Biomater 5:3007-3020

9. Jo YY, Kweon H, Kim DW et al (2017) Bone regeneration is associated with the concentration of tumour necrosis factor-alpha induced by sericin released from a silk mat. Sci Rep 7:15589

10. Kim JY, Choi JY, Jeong JH et al (2010) Low molecular weight silk fibroin increases alkaline phosphatase and type I collagen expression in MG63 cells. BMB Rep 43:52-56

11. Nayak S, Dey T, Naskar D, Kundu SC (2013) The promotion of osseointegration of titanium surfaces by coating with silk protein sericin. Biomaterials 34:2855-2864

12. Fujimoto $Y$, Fujita T, Kuramoto $N$ et al (2018) The role of interleukin-19 in contact hypersensitivity. Biol Pharm Bull 41:182-189

13. Song JE, Park SJ, Lee KY, Lee WJ (2018) Amniotic fluid HIF1alpha and exosomal HIF1alpha in cervical insufficiency patients with physical examination-indicated cerclage. J Matern Fetal Neonatal Med. https://doi. org/10.1080/14767058.2018.1432037

14. Vasilopoulos Y, Sourli F, Zafiriou E et al (2013) High serum levels of HIF1alpha in psoriatic patients correlate with an over-expression of $\mathrm{IL}-6$. Cytokine 62:38-39

15. Guo X, Zhu Z, Zhang W et al (2017) Nuclear translocation of HIF-1alpha induced by influenza $A(\mathrm{H} 1 \mathrm{~N} 1)$ infection is critical to the production of proinflammatory cytokines. Emerg Microbes Infect 6:e39

16. Bergers G, Benjamin LE (2003) Tumorigenesis and the angiogenic switch. Nat Rev Cancer 3:401-410

17. Jiang S, Li Y, Lin T et al (2016) IL-35 inhibits angiogenesis through VEGF/Ang2/ Tie2 pathway in rheumatoid arthritis. Cell Physiol Biochem 40:1105-1116
18. Fuster-Matanzo A, Manferrari G, Marchetti B, Pluchino S (2018) Wnt3a promotes pro-angiogenic features in macrophages in vitro: implications for stroke pathology. Exp Biol Med 243:22-28

19. Yeo EJ, Cassetta L, Qian BZ et al (2014) Myeloid WNT7b mediates the angiogenic switch and metastasis in breast cancer. Cancer Res 74 2962-2973

20. Khorshidi A, Dhaliwal P, Yang BB (2016) Noncoding RNAs in tumor angiogenesis. Adv Exp Med Biol 927:217-241

21. Gao SY, Zheng GS, Wang L et al (2017) Zoledronate suppressed angiogenesis and osteogenesis by inhibiting osteoclasts formation and secretion of PDGF-BB. PLoS One 12:e0179248

22. Xie H, Cui Z, Wang L et al (2014) PDGF-BB secreted by preosteoclasts induces angiogenesis during coupling with osteogenesis. Nat Med 20: $1270-1278$

23. Heldin CH, Westermark B (1999) Mechanism of action and in vivo role of platelet-derived growth factor. Physiol Rev 79:1283-1316

\section{Submit your manuscript to a SpringerOpen ${ }^{\circ}$ journal and benefit from:}

- Convenient online submission

- Rigorous peer review

- Open access: articles freely available online

- High visibility within the field

- Retaining the copyright to your article

Submit your next manuscript at $>$ springeropen.com 